\title{
EDUCAÇÃO EM RORAIMA: INSTITUCIONALIZAÇÃO ESCOLAR DE 1943 A 2001
}

\author{
Maria Edith Romano Siems-Marcondes ${ }^{1}$ \\ lattes.cnpq.br/4322158349617339
}

\begin{abstract}
Resumo: Este texto apresenta aspectos da trajetória histórica de institucionalização escolar ocorrida em Roraima do período de 1943, quando o Território Federal é implantado, até 2001, quando se consolida a primeira década de instalação do Estado de Roraima. Trata-se de uma análise documental em que apresentamos registros oficiais de criação de unidades escolares e sistematizamos dados de pesquisas anteriores. Na análise dos processos de constituição histórica da educação escolar em Roraima, identificamos que sua estruturação acompanha as políticas estabelecidas para a região, interligada às políticas expansionistas e de ocupação.
\end{abstract}

Palavras-chave: História da Educação; Expansão da escolarização; História da educação brasileira.

\section{EDUCATION IN RORAIMA: SCHOOL INSTITUTIONALIZATION FROM 1943 TO 2001}

\begin{abstract}
This text presents aspects of the historical trajectory of school institutionalization that occurred in Roraima in the period of 1943 , when the Federal Territory was implemented until 2001, when the first decade of the State of Roraima was consolidated. It is a documentary analysis in which we present official records of the creation of school units and systematize data from previous researches. In the analysis of the processes of historical constitution of school education in Roraima, we identified that its structuring accompanies the policies established for the region, linked to expansionist and occupation policies.
\end{abstract}

Keywords: History of Education; Expansion of schooling; History of Brazilian education.

1 Doutora em Educação Especial. Docente da Universidade Federal de Roraima (Brasil). Contato: edithromanos@hotmail.com. 


\section{Introdução}

O Estado de Roraima está localizado na porção mais setentrional do país, contando em seu território com o Monte Caburaí, ponto extremo norte do Brasil. Faz fronteira com a Venezuela e a Guiana Inglesa e foi um dos últimos territórios brasileiros a ser transformado em estado da federação, cuja efetiva instalação deu-se em janeiro de 1991.

Seu histórico de ocupação por populações não indígenas é bastante recente e não coincide com os processos históricos vivenciados no restante do país, permanecendo até o ano de 1980 com uma população inferior a 80.000 habitantes. Seu território ocupa $224.200 \mathrm{~km}^{2}$, extensão bastante próxima à registrada no estado de São Paulo, por exemplo, que conta com uma área de $248.200 \mathrm{~km}^{2}$.

Dificuldades de acesso, condições climáticas e as peculiaridades de uma natureza resistente à intervenção humana estão entre os fatores que levam a que essa ocupação só se intensifique a partir da intervenção direta dos governos militares que, no período da ditadura militar, adotaram políticas de incentivo à ocupação das terras da região amazônica, em especial a fronteiriça, na perspectiva do "integrar para não entregar".

Esse processo de ocupação através do incentivo à migração prossegue de maneira ascendente nos anos finais da década de 1980 e ao longo dos anos 1990, como reflexo das condições econômicas que se agravavam no restante do país. A criação das condições necessárias à instalação do Estado de Roraima abre um expressivo volume de cargos públicos em áreas especializadas que anteriormente eram supridas com equipes transitórias e vinculadas ao governo federal.

Entre as instituições e órgãos que aqui passam a sediar espaços e equipes próprias, o Estado tem a implantação de sua primeira instituição que oferta ensino superior, a Universidade Federal de Roraima, à qual se agregam anos depois a Universidade Estadual de Roraima e faculdades privadas de menor porte, possibilitando não só a formação dos quadros necessários à atuação no Estado, quanto a formação de um quadro de 
pesquisadores em áreas diversas, dentre eles, pesquisadores que desenvolvem estudos relativos aos processos históricos locais.

O objetivo deste estudo é analisar como se dá o processo de institucionalização da educação formal na cidade de Boa Vista, capital de Roraima, com ênfase no mapeamento do processo de criação das instituições escolares desde a instalação do Território Federal do Rio Branco em 1943, até a primeira década após a transformação do território federal em estado da federação (2001).

O texto está organizado em três partes. Na primeira analiso estudos que apresentam pistas da realização de processos educacionais pelos diferentes grupos missionários que pela região transitam entre os séculos XVIII e XIX. Na segunda parte apresento o processo de institucionalização escolar, tomando por base dados disponibilizados no Censo Educacional de 2010 e em documentos oficiais, como relatórios e planos de governo, correlacionando este processo de construção e implantação de escolas à expansão populacional trazida pelos fluxos migratórios. Na terceira apresentamos primeiras aproximações quanto ao processo de chegada do ensino superior em Roraima entendendo ser este um campo que demanda aprofundamento de estudos.

Entendemos ser esta sistematização da trajetória de institucionalização escolar relevante, ao possibilitar maior compreensão dos processos de expansão e impacto das demandas trazidas pelos fluxos migratórios que levaram à ocupação da região.

\section{História da Educação em Roraima: um campo de estudos em construção}

Os estudos históricos que se reportam à educação em Roraima apresentam, de maneira reincidente, um olhar sobre a educação indígena, área que se destaca no contexto local pela diversidade de etnias existentes na região e por suas conquistas pioneiras no campo da educação específica e de formação diferenciada de professores para suas escolas. 
São menos comuns os estudos referentes à História da Educação em área urbana e das práticas educacionais que se estabeleceram ao longo do processo de ocupação territorial para populações não indígenas. É uma situação até certo ponto compreensível, se considerarmos que a fixação de migrantes em volume numericamente expressivo só vai ocorrer em meados do século XX.

Embora já encontremos nos textos de Rice (1978) e de KochGrünberg (2003, 2005 e 2006) registro de atividades isoladas de educação na região, nos primórdios do século XX, é apenas após a implantação dos Territórios Federais, ocorrida em 1943, que estas se intensificam e institucionalizam como parte da estratégia de ocupação e de desenvolvimento, conforme apontaremos mais adiante.

Estudos que tomam como foco a história da educação em Roraima vem sendo desenvolvidos por pesquisadores vinculados, em sua maioria, à Universidade Federal de Roraima. Para o alcance de nossos objetivos neste artigo, recorremos prioritariamente a estes trabalhos como fontes primárias de informação.

Dos textos identificados que apresentam estudos históricos da educação em Roraima destacamos a dissertação de Macedo (2004); a monografia de Lima (2005) e a dissertação de Purceno (1999), cujo trabalho, refletindo sobre a constituição do perfil das personagens que chama de "professorinhas", aponta para registros de concepções e práticas que nos auxiliam na compreensão de contextos históricos em que a educação se desenvolve em Roraima.

Fundamentamos ainda nossos estudos, no trabalho de Freitas (1993), e na consulta a relatórios da Secretaria de Estado da Educação das décadas de 1970 a 1990 que nos oportunizaram uma maior compreensão do processo a partir da perspectiva dos registros oficiais de dados.

Macedo (2004, p. 16-17) afirma que seu trabalho tem por objetivo "desvendar algumas questões relevantes no processo de implantação e expansão das escolas públicas de Boa Vista" e que faz "um histórico sobre o processo de implantação das escolas públicas em Boa Vista na década 
de 1940”, e, além da análise do contexto geral, foca sua atenção no estudo do Grupo Escolar Lobo D'Almada.

Lima (2005, p. 12) destaca que seu trabalho tem por objetivo "compreender a significação da participação das mulheres professoras na História da Educação em Boa Vista, entre as décadas de 1950 a 1990, enquanto anseio de conquistar a oportunidade profissional”. Ao tratar deste tema, foca-se nas práticas pedagógicas da Escola São José e, por tratar-se essa de uma instituição confessional vinculada à Igreja Católica, finda por nos trazer elementos relevantes de análise sobre a presença religiosa na condução das políticas públicas de educação em Roraima.

Purceno (1999, p. 14-15) busca, pautando-se em entrevistas com educadores, recuperar narrativas que tratem das "práticas educacionais de Boa Vista a partir do cotidiano pedagógico, com memórias que nos chegam desde a década de 1950”. Através destas narrativas, discute a "instituição da 'professorinha', ou de uma imagem inferiorizante e normatizada da professora de crianças, nos discursos hoje, em Boa Vista".

Freitas (1993), ao buscar estruturar uma trajetória histórica das políticas administrativas de Roraima, retoma em seu texto questões relativas à estruturação do sistema público de educação e, ao apresentar o relato de sua vivência enquanto estudante, também dá indícios relevantes ao entendimento desta trajetória, em especial no tocante ao entendimento da estruturação do ensino superior e da formação de profissionais qualificados antes da chegada da Universidade a esta região.

\section{Educação como prática missionária}

A trajetória de constituição da educação em Roraima apresenta lacunas ainda a serem preenchidas por estudos mais aprofundados, que possibilitem o delineamento de seus caminhos com maior clareza. De maneira geral, o surgimento de atividades institucionalizadas no campo 
da educação no Brasil esteve associado à presença de ordens religiosas que, com o propósito de catequizar e "capturar" almas, realizavam ações de educação formal em seus espaços de ação.

Em Roraima, a princípio, temos também o registro de atividades desta natureza. Há, no entanto, um diferencial expressivo em relação ao papel das ordens religiosas no processo de desenvolvimento da educação roraimense. Em nosso Estado, a presença de ordens religiosas se deu de maneira descontinua com a predominância de diferentes grupos religiosos em diferentes momentos, sem uma relação de progressão ao longo do tempo.

Os textos que tratam dos primeiros movimentos no campo da Educação reportam-se às atividades desenvolvidas por missionários de diferentes ordens, como os Carmelitas, Beneditinos e Missionários da Consolata. No destaque de Purceno (1999, p. 59) "a participação de instituições religiosas estende-se ainda hoje na educação das mais antigas escolas de Boa Vista e de algumas comunidades indígenas”.

$\mathrm{Na}$ análise dos textos que se reportam ao desenvolvimento da educação em Roraima, em um primeiro momento encontramos registros da presença de missionários carmelitas que se retiram ao final do século XVIII (1725-1788). Ao longo do século XIX, os serviços religiosos, que historicamente se confundiram com os de educação, passam a ser exercidos por Missionários Apostólicos. O destaque deste período é a fundação, em 1892 da Paróquia de Nossa Senhora do Carmo de Boa Vista, na sede da fazenda do mesmo nome, que fortalecerá a consolidação do que virá a tornar-se o maior município da localidade.

No século XIX, há também o registro de passagem de representantes de ordens religiosas diversas, como os Capuchinhos e os Franciscanos (Assis e Paula, 1980). A primeira Ordem sobre a qual encontramos referências é a dos missionários da Ordem de Nossa Senhora de Mont Carmel, os padres Carmelitas que, vindos do Rio Negro, já em 1725 se estabelecem ao longo do Rio Branco. Como parte dos esforços europeus para efetivar a posse territorial, fundam missões ao longo do Rio Branco. Essas missões, no entanto, têm duração efêmera e, segundo 
Santilli (1994, p. 45), não é possível afirmar que tenham realizado um trabalho específico de evangelização dos índios neste período.

Cirino (2009, p. 47-49), apoiado em documentos do Centro de Informação da Diocese de Roraima e relatórios da Fundação Nacional do Índio (FUNAI), destaca: a fragilidade do trabalho desenvolvido pelos carmelitas; a decadência dos trabalhos desses missionários, em decorrência das insurreições indígenas, que levaram à extinção dos primeiros povoamentos então existentes com destaque para o episódio que ficou conhecido como da "praia do sangue".

Somente em 1909 vemos a fixação da Missão Beneditina - de base alemã - que permanece em atividade até meados do século XX, quando repassam parte de suas atividades - inclusive escolas - aos Missionários da Consolata (Assis e Paula, 1980).

Não era um momento em que a noção de educação como Direito Social estivesse estabelecida. Como aponta Cury (2005, p. 4),

Apesar de o direito à educação não constar dos chamados direitos naturais, será no contexto do nascimento da sociedade moderna que a instrução lentamente ganhará destaque. Ora ela é o caminho para que as luzes (universais) se acendam em cada indivíduo a fim de que todos possam usufruir da igualdade de oportunidades e avançar diferencialmente no sentido do mérito, ora ela é uma função do Estado a fim de que o acesso individual à educação não venha a tornar-se privilégio de poucos.

Como parte desse processo de implantação de uma estrutura de educação na região, Koch-Grünberg (2003), na viagem que realiza pelo extremo norte entre os anos de 1911-1913, relata seu contato com ações

\footnotetext{
${ }^{2} \mathrm{O}$ episódio conhecido como Praia do Sangue aconteceu em 1789 na região próxima à atual Cachoeira do Bem-Querer, como reação dos portugueses a episódios de insurreição que vinham sendo apresentados pelos indígenas, revoltados com a exploração e maus tratos que lhe eram impingidos. Em conflitos anteriores entre portugueses e indígenas, foi registrada a morte de um diretor português, soldados de um destacamento e alguns moradores. Na reação, um destacamento de soldados portugueses fortemente armados atacou violentamente indígenas das tribos Wapixana e Paraviana em um episódio de tal violência que "tingiu" as águas com o sangue dos mortos, em sua quase totalidade indígenas (SANTOS, 2010, p. 179).
} 
educacionais que aqui presenciou. Relata que se deslocou até a sede da missão beneditina, lá permanecendo por alguns dias.

Segundo Koch-Grünberg, Dom Gerardo van Caloen recebeu, em 1908, diretamente do papa Pio X, a região do rio Branco como "prelazia". Em seu relato, Koch-Grünberg (2003, p. 133-134) destaca a recepção negativa que os padres tiveram por parte das lideranças locais 3 e descreve o processo de instalação da missão:

A missão comprara uma propriedade pouco abaixo de Boa Vista, para nela construir um mosteiro com igreja e escola, mas a constante inimizade não permitiu que isso se concretizasse; os padres viram-se até obrigados a se retirar mais ainda rio acima, para Capela, onde um de seus amigos, o antigo comandante de fronteira, coronel Paulo Saldanha, pôs sua propriedade à disposição deles. Em fevereiro de 1910 a missão sofreu um duro golpe com a morte repentina de dois padres, vítimas de febre quando em viagem para a Europa. Na mesma época, teve início a construção da sede da missão no alto Surumu, chamada de São Gerardo de Brogna em honra ao fundador da missão beneditina no rio Branco. Ela deveria, aos poucos, transformarse em mosteiro, em torno do qual todo o trabalho da missão se cristalizaria.

Esta sede da missão, no alto Surumu, permanecerá e se tornará, ao longo do século, em um ponto importante de mobilização das comunidades indígenas em especial nos anos 1970-1980 (Vieira, 2007). Em relação às atividades educacionais ali realizadas, registra-se que são direcionadas às populações indígenas, mas desenvolvidas em uma lógica que à luz dos olhares que construímos na atualidade sobre o que deva ser a educação de povos indígenas, causam incômodo. O aprendizado da lín-

3 Logo após sua chegada, os missionários tiveram que enfrentar grande inimizade, até mesmo ataques efetivos, que punham sua vida em risco e ameaçavam sufocar a obra que apenas germinava. Em Manaus e no Rio desencadeou-se na imprensa uma furiosa contenda contra os missionários, que se excedia em acusações da pior espécie. $\mathrm{Na}$ mesma época, soldados da polícia estadual em Boa Vista exerciam um regime de terror no Rio Branco, ao perseguir todos que simpatizavam com os padres. No início de 1910 chegaram até a disparar vários tiros contra a casa em que os missionários moravam então, e Padre Adalbert só escapou da morte por um triz. Por fim, o governo federal interveio e enviou uma tropa a São Joaquim para proteger os padres. (KOCH-GRUNBERG, 2003, p. 133-134). 
gua materna de cada comunidade indígena é um ponto que favorece o contato dos missionários com as comunidades, mas o ensino da língua portuguesa é estratégia política de construção de uma identidade territorial.

Acredita-se que o processo educativo respeitava os postulados cristãos comuns às missões catequizadoras, que estavam mais preocupadas com o ensino da língua portuguesa a fim de ocupar as terras e evangelizar os aborígenes com a "fé cristã", na "obediência divina". Baseado na historiografia local, os missionários aprendiam a língua através das canções dos povos indígenas e ensinavam as crianças das malocas, músicas inseridas nos novos códigos de leitura; assim entendiam estar preparando-os para a civilização e para a integração nacional. Percebe-se que a educação adotava os instrumentos culturais europeus visando mudanças de hábitos, costumes e tradições. Eram as transformações tanto material como espiritual exigidos pela nova composição social que insurgia na Amazônia. (LIMA, 2005, p. 37).

No relato de Koch-Grünberg (2003, p. 135), referindo-se a fatos presenciados em 1911, mas no mesmo local:

Certa manhã assisto à aula na escola. Os meninos estão lendo Makuschí e português na lousa. Quando Pe. Adalbert faz uma pergunta, para alegria geral, dou a resposta certa em Makuschí, a seguir desapareço bem depressa. Apesar da inteligência natural da maioria dos meninos indígenas, custa muito trabalho e infinita paciência acostumar estes traquinas à matéria que lhes é totalmente estranha e a ficarem sentados.

Cirino (2009, p. 170) descreve as práticas pedagógicas desenvolvidas pelos beneditinos na missão, totalmente atreladas ao interesse na catequização e conversão dos indígenas, tomado o catecismo ilustrado como um recurso eficaz. Destaca entre os documentos a que teve acesso:

Um registro de D. Alcuino Meyer é tão grotesco quanto as cenas observadas por Koch-Grünberg no início do século. O missionário afirma que não agüentava mais recitar, explicar e entoar os cantos litúrgicos e prossegue dizendo que, quando se retirava das malocas, os índios seguiam-no, até uma determinada distância, recitando em voz alta o Pai-Nosso, a Ave-Maria e o Credo. 
Em outro momento de seu texto, Koch-Grünberg relata atividades desenvolvidas pela esposa de um fazendeiro, alfabetizando, em sua casa, crianças do entorno, provavelmente filhos também de outros fazendeiros e colonos. São indícios de um movimento que deveria se reproduzir em outras residências rurais e urbanas, meios de enfrentamento à ausência do Estado como indutor ou financiador de ações educacionais, a exemplo do que acontecia em outras regiões do país, em que a educação inicial das elites se dava no âmbito doméstico com preceptores e a formação em nível mais elevado se efetivava em outros países.

\section{Institucionalização escolar}

Fora do âmbito das missões religiosas, com a criação do município de Boa Vista em 1890, acompanhando os movimentos nacionais que se encaminhavam no sentido de entender-se a educação como ação que deveria ser pública, laica e gratuita, há também o registro da existência de professores tidos como mestre-escola. A revista Diretrizes, publicada em Boa Vista em 30 de janeiro de 1991, destaca as figuras de João Capistrano da Silva Mota, Alfredo Venâncio de Souza Cruz e Diomedes Souto Maior como pioneiros neste campo.

João Capistrano da Silva Mota foi o primeiro prefeito do então recém-criado município de Boa Vista e acumulava as funções de Prefeito, Juiz de Paz, Fazendeiro e Promotor de Justiça. Diomedes Souto Maior foi dos mais reconhecidos professores vindo a nominar inclusive a primeira escola pública oficial criada no município. É de se supor que estes mestre-escola realizassem suas atividades junto aos filhos de colonos e fazendeiros, em espaços residenciais próprios ou de seus contratantes, já que, até o momento, não localizamos registros da existência de espaços oficiais destinados à Instrução Pública na cidade de Boa Vista antes de sua transformação em Território Federal.

Em âmbito nacional, em 1931, foi criado o Ministério da Educação e Saúde Pública. Era o período do Governo Vargas, em que se fortalecem 
as discussões sobre a responsabilidade governamental pela oferta de serviços educacionais em perspectiva pública, laica e gratuita.

Analisando os dados do Censo Escolar 2010, que apresenta informações relativas às escolas existentes em Roraima, apresentamos ao final deste tópico, uma tabela com os Decretos de Criação e respectivas datas de criação de escolas (até 2001) atualmente em funcionamento.

Entrevistas realizadas com professoras atuantes na Educação Especial na década de 1970 trazem o indicativo de existência de outras escolas atualmente extintas (como a escola Murilo Braga, por exemplo), sobre as quais não conseguimos obter maiores detalhes. Com os dados disponíveis, observamos que o processo de expansão desenvolve-se aos saltos, com períodos de intensa atividade e períodos em que nenhuma nova instituição é criada.

Na década de 1920, a missão beneditina, que até então tinha suas atividades concentradas na conversão de indígenas ao catolicismo em missões distantes de Boa Vista, passa a direcionar suas atividades para esta localidade que, à época, já registrava cerca de dois mil habitantes. No destaque de Lima (2005, p. 37), naquela época "foi comprada em Boa Vista uma casa para os padres" e "alugada uma casa para as freiras da congregação Beneditina [...] que trabalhavam incansavelmente em prol da educação feminina na antiga escola São José”, fundada em outubro de 1924 como Escola da Prelazia4, e construída no centro do Município de Boa Vista, no período em que a liderança diocesana era exercida por D. Pedro Eggerath.

Referindo-se ao esforço dos beneditinos, Lima (2005, p. 37) destaca a chegada, em 1926, do evangelizador D. Alcuino Meier, que aqui atuou por 22 anos e que, "além dos trabalhos missionários, administrava os bens materiais da Prelazia e dirigia um patrono de jovens no bairro Calunga". É um missionário cujo trabalho educador é enfaticamente apontado pelos pesquisadores que vem se debruçando sobre os

\footnotetext{
${ }^{4}$ A Escola da Prelazia foi um estabelecimento católico de ensino, primeiramente direcionado aos indígenas, em seguida o aprendiz espaço feminino do Território Federal do Rio Branco (LIMA, 2005, p. 49).
} 
documentos aos quais se teve acesso até o momento e que dependem da disponibilização pelos atuais dirigentes missionários.

Entre os anos de 1945 e 1949, temos a implantação oficial de várias das escolas que até hoje são representativas do sistema estadual de educação, na rede pública de ensino do Território Federal. A primeira delas, segundo Macedo (2004), foi a escola mista Professor Diomedes Souto Maior 5 , em decreto assinado pelo primeiro governador territorial, o capitão Ene Garcez dos Reis. A segunda, criada por decreto do mesmo governador, foi o Grupo Escolar Lobo D'Almada ${ }^{6}$. Há, ainda, o registro de proposição via decreto, de várias outras unidades, nem todas postas em funcionamento:

Através dos Decretos n.os 11, 12, 16 e 17, foram criadas em Boa Vista: 7 Escolas Mistas Agrupadas, 1 Escola Isolada Mista, 1 Escola Noturna Feminina e 3 Escolas Noturnas Masculinas. No interior foram criadas 9 Escolas Isoladas Mistas. As sete escolas mistas foram integradas ao Grupo Escolar Lobo D'Almada. As noturnas foram unificadas no mesmo estabelecimento. As escolas admitiam rapazes e moças que trabalhavam durante $o$ dia. A Escola Isolada Mista recebeu o nome de Professor Diomedes Souto Maior. Dessas 21 escolas, quatro deixaram de funcionar por falta de profissionais ou de sede apropriada: três do interior e uma da capital, cuja edificação não foi concluída no prazo previsto.

\footnotetext{
${ }^{5}$ Nos registros da Divisão de Estatísticas da Secretaria Estadual de Educação há divergência nas datas dos Decretos de Criação apontando ter sido a escola Lobo D'Almada criada em abril de 1945 e a Diomedes em agosto do mesmo ano. Na Revista Diretrizes, publicada no Centenário do Município de Boa Vista cita-se a criação, em 1934, de uma escola mista municipal que tinha como professor Aristóteles de Lima Carneiro. Não obtivemos, no entanto, documentos que possibilitassem elucidar a razão destas divergências.

${ }^{6}$ Elucidativo do modo em que se deu a criação da rede pública de educação do Território é o caso do Grupo Escolar Lobo D’Almada. Suas primeiras instalações foram as de uma casa residencial, alugada por um ano, cujas dependências foram adaptadas. O proprietário entregou as chaves do estabelecimento no dia 15 de abril de 1946 e, logo depois, iniciaram-se as matrículas no pavilhão lateral. A solenidade de instalação ocorreu no dia 19 de abril, com a presença do governador, de oficiais e do povo em geral. O corpo docente da escola era composto por três professores. A relação era de 129 discentes para cada docente, os quais foram distribuídos em cinco salas para uma ampla varanda com pátio térreo, que separava um pavilhão, com duas salas de 7,00x 5,00 metros.
} 
Em 1949, já no governo do capitão Clóvis Nova da Costa, cria-se o Curso Normal Regional Monteiro Lobato e, no mesmo ano, já no governo de Miguel Ximenes de Melo, o Grupo Escolar Oswaldo Cruz. Macedo (2004) destaca ainda o funcionamento de duas Escolas Noturnas, cuja regência era feita por dois coadjuvantes de ensino separadas para atendimento a alunos dos sexos masculino e feminino. Aponta, ainda, para a existência da escola Fernão Dias, na "Serra do Murupu, no lugar chamado Baixa Verde, com cerca de 46 alunos, sob a responsabilidade de um leigo que já havia adquirido experiência em Boa Vista”.

Dados da Secretaria Estadual de Educação mostram a incorporação do Colégio São José como escola pública territorial através do Decreto $\mathrm{n}^{\mathrm{o}}$ 48, de 05 de junho de 1947. Há registros também de que o Ginásio Euclides da Cunha, estabelecimento que oferecia ensino secundário tenha sido criado em 1948/1949, embora sua incorporação pelo governo territorial só venha a aparecer, nos documentos da Secretaria Estadual de Educação no Decreto 21, de 07 de junho de 1977.

Acompanhando o movimento de desenvolvimento do Território Federal do Rio Branco, que apresenta entre os anos de 1950 e 1970, um crescimento pouco acentuado, não há registro do surgimento de escolas novas de grande porte na área urbana, apenas a criação, na década de 1960, de Escolas Indígenas e em localidades do interior.

Na segunda metade da década de 1960, com a prioridade dada a esta região como fronteira estratégica para a manutenção da segurança nacional, em face da instabilidade na região caribenha, que já apontamos anteriormente, e da entrada do regime ditatorial, com a priorização do "desenvolvimento" e da "segurança"7, vemos uma retomada no processo de expansão das escolas.

\footnotetext{
${ }^{7}$ No entendimento de Kaufmann e Martins (2009, p. 258): “certamente, as políticas da educação assumiram também os registros militarizados (militares em cargos ministeriais e dirigentes, assim como em conselhos e comissões), intencionalidades destrutivas e punitivas (exílios, desaparecimentos, controles, sanções, expulsões, censuras). E, também enfatizamos a necessidade de produzir uma "nova ordem educativa", consequente aos pilares ideológicos do regime".
} 
Tabela 1 - Escolas Territoriais - 1945 a 1965. Fonte: Censo Escolar 2010 Educacenso. Utilizamos a denominação destes estabelecimentos no ano de 2012.

\begin{tabular}{ccc}
\hline Decreto & Data & Nome \\
\hline 06 & $19 / 04 / 1945$ & Escola Estadual Lobo D’Almada \\
\hline 11 & $20 / 08 / 1945$ & Escola Estadual Diomedes Souto Maior \\
\hline 42 & $04 / 04 / 1946$ & Escola Estadual Indígena Índio Ajuricaba \\
\hline 89 & $05 / 06 / 1947$ & Escola Estadual São José \\
\hline 96 & $12 / 08 / 1949$ & Escola Estadual Escola Estadual Monteiro Lobato \\
\hline 18 & $10 / 02 / 1963$ & Escola Estadual Indígena Nilo José de Melo \\
\hline 06 & $23 / 01 / 1964$ & Escola Estadual Indígena José Aleixo Ângelo \\
\hline 18 & $28 / 07 / 1965$ & Escola Estadual Indígena Homero Cruz \\
\hline
\end{tabular}

Do início da chamada fase aeronáutica (1964-1985), acompanhando o período considerado como de regime ditatorial, ao fim do período territorial, temos uma expansão intensa no volume de escolas, em especial na região central e bairros próximos ao espaço que atualmente se constitui como centro da cidade. Primeira desta fase, a Escola Costa e Silva, criada em julho de 1971, marca um processo de criação de outras sete escolas, atualmente de médio e grande porte.

Na década de 1980, foram 15 as escolas criadas, já em bairros mais distantes da região central, um indicativo dos efetivos resultados do incentivo à migração, que inclui a abertura de estradas, construídas pelos próprios militares, e distribuição de terras em projetos de assentamentos, com a consequente expansão também de funções nos setores público e de serviços que levam à ampliação de populações também em área urbana. 
Tabela 2 - Escolas Territoriais. Período aeronáutico ao fim do período territorial. Fonte: Censo Escolar 2010 - Educacenso. Utilizamos a denominação destes estabelecimentos no ano de 2012.

\begin{tabular}{|c|c|c|}
\hline Decreto & Data & Nome \\
\hline 16 & 01/07/1971 & Escola Estadual Presidente Costa e Silva \\
\hline 30 & 05/06/1973 & Escola Estadual Penha Brasil \\
\hline 97 & $25 / 03 / 1975$ & Escola Estadual Ana Libória \\
\hline 12 & 24/03/1977 & Escola Estadual Gonçalves Dias \\
\hline 20 & $07 / 06 / 1977$ & Escola Estadual São Vicente de Paula \\
\hline 21 & 07/06/1977 & Escola Estadual Euclides da Cunha \\
\hline 13 & 21/07/1977 & Escola Estadual 31 de março \\
\hline 27 & 24/o8/1977 & Escola Estadual Ind. Prof Genival Thomé Macuxi \\
\hline 27 & 24/o8/1977 & Escola Estadual Indígena Senador Felintro Muller \\
\hline 27 & $24 / 08 / 1977$ & Escola Estadual Indígena Paulo Augusto Silva \\
\hline 51 & $10 / 11 / 1978$ & Escola Estadual 13 de setembro \\
\hline 79 & 05/09/1980 & Escola Estadual Dom José Nepote \\
\hline 80 & 05/09/1980 & Escola Estadual Hidelbrando Ferro Bitencourt \\
\hline 13 & $07 / 12 / 1983$ & Escola Estadual Camilo Dias \\
\hline 95 & $16 / 12 / 1983$ & Escola Estadual Princesa Isabel \\
\hline 97 & $16 / 12 / 1983$ & Escola Estadual Prof ${ }^{a}$ Maria das Dores Brasil \\
\hline 99 & $19 / 12 / 1983$ & Escola Estadual Profa Diva Alves Lima \\
\hline 24 & $25 / 06 / 1984$ & Escola Estadual Buriti \\
\hline 07 & 07/02/1985 & Escola Estadual Barão de Parima \\
\hline 1310 & $14 / 08 / 1986$ & Escola Estadual Jaceguai Reis Cunha \\
\hline 79 & 07/11/1986 & Escola Estadual Vitória Mota Cruz \\
\hline
\end{tabular}


79 07/11/1986 Escola Estadual Maria das Neves Rezende

\begin{tabular}{ccc}
78 & $31 / 10 / 1986$ & Escola Estadual Girassol \\
& $31 / 08 / 1988$ & Escola Estadual Mário David Andreazza \\
\hline 26 & $12 / 10 / 1988$ & Escola Estadual Prof. Antonio Ferreira de Souza \\
\hline 26 & $12 / 10 / 1988$ & Escola Estadual Idarlene Severino de Souza \\
\hline 25 & $12 / 10 / 1988$ & Escola Estadual Indígena Índio Dionísio Figueiredo \\
\hline 25 & $12 / 10 / 1988$ & Escola Estadual Indígena Lino Augusto da Silva \\
\hline
\end{tabular}

Os dados disponibilizados pelo Educacenso de 2010 destas escolas, criadas entre os anos em que o Território Federal vivenciou seu controle por militares da aeronáutica, não apresentam registros de dados referentes à Escola de Educação Especial, nem da Escola de Audiocomunicação, atualmente extintas. Entretanto, estudos históricos como o de Siems (2013) apontam que, em sua criação estes espaços foram categorizados especificamente como escolas e não como "centros" de atendimento, modelo em que se encontram na atualidade.

Documentos existentes como um relatório governamental produzido em 1977 (RORAIMA, 1977) apresenta a matrícula inicial por nível e modalidade de ensino, em que constam o Centro de Educação Especial de Boa Vista, com 186 alunos, 45 professores e 18 salas de aula; a Escola de Audiocomunicação, com 45 alunos e nove professores em cinco salas de aula, e o Centro de Educação Especial Denize Messias Santos de Caracaraí, com 34 alunos e 12 professores, em oito salas de aula.

Com a transformação do Território Federal em Estado, ocorre um investimento de recursos expressivos que seriam destinados à criação de uma infraestrutura que assegurasse condições para sua sustentabilidade econômica autônoma, com menor dependência de recursos do governo federal e neste período, o investimento na realização de obras de base, como a construção de escolas, foi a tônica. 
Tabela 3 - Escolas Estaduais no período de 1990 a 2000.

Fonte: Censo Escolar 2010 - Educacenso. Utilizamos a denominação destes estabelecimentos no ano de 2012.

\begin{tabular}{|c|c|c|}
\hline Decreto & Data & Nome \\
\hline 1288 & 28/09/1990 & Escola Estadual Indígena Albino Tavares \\
\hline 1289 & 28/09/1990 & Escola Estadual Carlos Drumond de Andrade \\
\hline 1289 & 28/09/1990 & Escola Estadual Jesus Nazareno de Souza Cruz \\
\hline 1289 & 28/09/1990 & Escola Estadual Maria dos Prazeres Mota \\
\hline 1289 & 28/09/1990 & Escola Estadual Antonio Carlos da Silva Natalino \\
\hline 85 & $10 / 09 / 1991$ & Escola Estadual Pedro Elias Albuquerque Pereira \\
\hline 114 & $12 / 09 / 1991$ & Escola Estadual Hélio da Costa Campos \\
\hline 375 & 24/09/1992 & $\begin{array}{l}\text { Escola Estadual Major Alcides } \\
\text { Rodrigues dos Santos }\end{array}$ \\
\hline 421 & $27 / 11 / 1992$ & Escola Estadual Ulisses Guimarães \\
\hline 41 & 26/01/1993 & Escola Estadual Caranã \\
\hline 780 & 27/07/1994 & Escola Estadual Ayrton Senna da Silva \\
\hline 936 & 03/05/1995 & Escola Estadual Maria Nilce Macedo Brandão \\
\hline 957 & $31 / 05 / 1995$ & Escola Estadual América Sarmento Ribeiro \\
\hline 1064 & 06/10/1995 & Escola Estadual Prof. ${ }^{a}$ Antonia Coelho de Lucena \\
\hline 1063 & 05/10/1995 & Escola Estadual Prof. ${ }^{a}$ Maria de Lourdes Neves \\
\hline 1070 & $16 / 10 / 1995$ & Escola Estadual Luiz Ribeiro de Lima \\
\hline 1193 & $18 / 03 / 1996$ & $\begin{array}{c}\text { Escola Estadual Prof. }{ }^{\text {a Francisca }} \\
\text { Elzika de Souza Coelho }\end{array}$ \\
\hline 1027 & $15 / 04 / 1996$ & Escola Estadual Olavo Brasil Filho \\
\hline 1282 & 04/06/1996 & Escola Estadual Voltaire Pinto Ribeiro \\
\hline $\mathrm{s} / \mathrm{n}$ & $5 / 08 / 1996$ & Escola Estadual Fagundes Varela \\
\hline
\end{tabular}




\begin{tabular}{|c|c|c|}
\hline 79 & 07/11/1996 & Escola Estadual Tancredo Neves \\
\hline 1534 & 16/04/1997 & $\begin{array}{l}\text { Escola Estadual Prof. }{ }^{\text {a }} \text { Raimunda } \\
\text { Nonato Freitas da Silva }\end{array}$ \\
\hline 1660 & 18/o8/1997 & Escola Estadual Prof. ${ }^{a}$ Wanda David Aguiar \\
\hline 1824 & $30 / 01 / 1998$ & Escola Estadual Maria Sonia de Brito Oliva \\
\hline 3385 & 08/03/1999 & 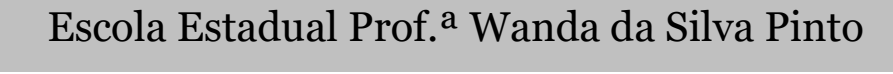 \\
\hline 3744 & $16 / 02 / 2000$ & Escola Estadual Prof. Carlos Casadio \\
\hline 4049 & $30 / 10 / 2000$ & Escola Estadual Prof. Severino G. G. Cavalcante \\
\hline
\end{tabular}

O processo de criação de escolas de educação sinaliza a tentativa de resposta às necessidades educacionais da população que aqui se instalava. Em termos populacionais, dados do censo demográfico, disponibilizados pelo Instituto Brasileiro de Geografia e Estatística - IBGE, que apontavam a existência, em 1950, de uma população de 17.834 habitantes, e em 1960, de 28.304 habitantes, mostram em 1970 chegamos a 40.885 e, a partir daí, um impacto expressivo de processos migratórios incentivados pelo governo ditatorial militar em seu esforço de ocupação da região amazônica, chega-se em 1980 a 79.159 habitantes. Em 1991, primeiro ano de instalação do Estado de Roraima, vemos essa população praticamente triplicar, chegando a 217.583 habitantes, em uma curva que prossegue ascendente e que registra, em 2000, 324.397 habitantes.

A construção de prédios escolares realiza-se com relativa facilidade, mas seu funcionamento eficaz ressente-se, no entanto, com a limitação de profissionais de educação com a qualificação mínima requerida para a realização de uma docência e gestão escolar qualificadas.

São imensas as dificuldades de contratação de professores e demais profissionais com formação em nível superior, considerando-se a inexistência de instituições que oferecessem formação em nível superior até a década de 1990, o que interfere diretamente também no processo migratório de profissionais de outras regiões do país que para cá deslocam-se para a ocupação desses postos de trabalho. 
As ações desenvolvidas no âmbito da educação básica requerem a presença de profissionais aptos à docência e atividades de gestão do sistema e de apoio aos educandos e professores que, para seu desenvolvimento demandariam a formação destes profissionais em nível superior, ponto nevrálgico no processo de instalação do Estado que abordaremos em nosso próximo tópico.

\section{Ensino Superior em Roraima}

Até final da década de 1960, todos os que quisessem cursar o ensino superior deveriam deslocar-se a outros Estados da Federação. São reincidentes registros como os de Freitas (1993), de que "filhos da terra" eram incentivados à realização de estudos em outros estados, inclusive com a possibilidade de instalação em residências universitárias, como as implantadas em Belém e em Manaus, custeadas com recursos governamentais e o compromisso de retorno, quando formados, aos quadros profissionais do setor público.

Há registros, como os de Freitas (1993) e Santos (2004), da existência de bolsas de estudo via Superintendência do Desenvolvimento da Amazônia - SUDAM, e outras formas de apoio financeiro a estudantes roraimenses aprovados em outras universidades. Além disso, algumas universidades federais, como a própria Universidade Federal de Santa Maria e a Universidade Federal do Ceará (RORAIMA, 2006), aqui realizaram processos seletivos de ingresso na modalidade vestibular e, quando aprovados, os alunos recebiam apoio governamental na forma de bolsas de estudos para instalação no estado sede da universidade.

Seguindo a lógica de ocupação do Governo Territorial, conduzido pelos militares da Aeronáutica, na perspectiva anteriormente citada do "integrar para não entregar", ocorre a instalação, em $1 .^{\circ}$ de agosto de 1969, de acordo com informações constantes no site da própria UFSM, de um Campus Avançado da Universidade Federal de Santa Maria UFSM, também com a oferta de cursos destinados à formação de 
professores. Eram cursos que funcionavam em regime especial, com aulas intensivas nos períodos de férias e recessos escolares.

Outra medida de impacto local foi a ocorrência, nos primórdios da década de 1970, de um convênio do Governo Territorial com a Universidade do Amazonas que oportuniza a realização de cursos de suplência para os professores do ensino de $1^{\mathrm{O}}$ e $2^{\mathrm{O}}$ graus nas áreas de Comunicação e Expressão, Matemática, Ciências Físicas e Biológicas, História e Geografia (RORAIMA, 2006). A tônica na formação de professores irá acompanhar o processo de implantação do ensino superior em Roraima, repetindo-se em todas as demais iniciativas que se estabelecem tendo a lógica da docência como demanda inicial.

Outros convênios foram sendo efetivados pelo governo do Território Federal com universidades, como a Federal de Pernambuco e a Federal do Pará e há iniciativas no sentido de se constituir a Fundação de Educação, Ciência e Cultura de Roraima - FECEC, órgão que se projetava como embrionário para a constituição de uma futura universidade local.

Em 12 de setembro de 1985, a Lei Federal 7.364 autoriza a criação da Universidade Federal de Roraima, mas essa só se efetiva a partir do Decreto Federal 98.127/88 que dispõe sobre a instituição da Universidade como Fundação Pública. Este Decreto, da lavra do Presidente José Sarney, foi, no relato do Senador Mozarildo Cavalcanti, parte das negociações que envolveram a votação favorável da bancada federal roraimense à proposta de extensão do mandato presidencial de quatro para cinco anos, naquela ocasião, e veio associada a um pacote de medidas e iniciativas que asseguraram sua efetiva implantação e início de atividades.

O estudo do processo histórico de instalação e funcionamento da Universidade Federal, bem como da Universidade Estadual e demais instituições de ensino superior privada que a ela se agregam ao final dos anos 1990, ainda é inicial, inclusive pela juventude de sua existência. Entretanto, o impacto da existência dessas instituições no contexto local é significativo com reflexos inclusive, na qualificação e diversificação das ofertas educativas da educação básica. 


\section{Considerações finais}

Analisando-se os processos de constituição histórica da educação escolar em Roraima, vemos que sua estruturação acompanha as políticas macro estabelecidas para a região, compondo importante elemento nas políticas expansionistas e de ocupação das fronteiras da região amazônica.

Os três fluxos de expansão da criação de escolas estão intrinsecamente relacionados a fases em que Roraima assume posição de destaque nas políticas governamentais em âmbito federal, a saber: no processo de implantação do território federal; nos anos finais da ditadura militar e nos períodos imediatamente anterior e subsequente à transformação do Território Federal em Estado da Federação, quando vivencia-se uma intensificação dos processos migratórios internos do Brasil com aportes de recursos federais para a construção de uma estrutura governamental própria.

Somente nesta etapa da passagem de território a estado é que se registra a criação de instituições de ensino superior que irão também possibilitar a constituição de um corpo de professores, gestores e técnicos especializados em condições de dar sustentação aos processos de institucionalização escolar.

Identificamos ainda um campo fértil de estudos e pesquisas a serem desenvolvidas no tocante à história da educação em Roraima, mas pretendemos ter trazido aqui nossa contribuição apresentando, neste artigo, referências de base dos registros documentais ora disponíveis.

\section{Referências}

ASSIS, A. A.; PAULA, C. R. Município de Boa Vista. Secretaria de Educação e Cultura/Departamento de Assuntos Culturais - Divisão de Ensino Superior, Território Federal de Roraima, 1980. 
BRASIL. Ministério da Educação e Cultura, Secretaria Geral, Secretaria de Informática, Serviço de Estatística da Educação e Cultura, Estatísticas Educacionais da Educação e Cultura: 1976/77. Editado pela Fundação Movimento Universitário de Desenvolvimento Econômico e Social MUDES: Rio de Janeiro, 1980.

CIRINO, C. A. M. A "boa nova" na língua indígena: contornos da evangelização dos wapischana no século XX. Boa Vista, EDUFRR, 2008. CURY, C. R. J. Os fora de série na Escola. Campinas: Armazém do Ipê (Autores Associados), 2005.

FREITAS, A. A história política e administrativa de Roraima: de 1943 a 1985. Manaus: Editora Umberto Calderaro, 1993.

KOCH-GRÜNBERG, T. Do Roraima ao Orinoco. V. I, São Paulo: Editora UNESP, 2003.

- A distribuiçãa dos povos entre rio Branco, Orinoco, rio Negro e Yapurá. Manaus: Editora INPA/EDUA, 2006.

. Dois anos entre os indígenas: viagens no noroeste do Brasil (1903-1905). Manaus: Editora da Universidade do Amazonas/FSDB, 2005 .

LIMA, A. A. Gênero e docência: trajetórias de saberes e poderes nas relações cotidianas em Boa Vista (1950/1990). Monografia (Especialização em História Regional), Universidade Federal de Roraima, Boa Vista, 2005.

MACEDO, I. R. D. A Implantação e a expansão das escolas públicas em Boa Vista na década de 1940. Dissertação (Mestrado em História), Universidade Federal do Rio de Janeiro, Rio de Janeiro, 2004.

PURCENO, S. S. Entre a vontade e o poder: vida pedagógica, silêncio e criação do sujeito ("Professorinhas" em Boa Vista - RR). Dissertação (Mestrado em História). Universidade Federal de Santa Catarina, Florianópolis, 1999.

RICE, A. H. Exploração da Guiana Brasileira. São Paulo: EDUSP, 1978. RORAIMA. Conselho Estadual de Educação. Parecer da Câmara de Educação Superior do Conselho Estadual de Educação de Roraima $\mathrm{n}^{\mathrm{o}}$ 34/o6. Aprovado em 15/08/2006.

SANTILLI, P. As fronteiras da República. São Paulo: NHI/USP-FAPES, 1994.

SANTOS, M. J. Em busca da terra: migração, organização e resistência na política de colonização no sudeste de Roraima (1970-1990). Dissertação (Mestrado em História), Universidade Federal do Amazonas, Manaus, 2010. 
SANTOS, N. P. D. Políticas públicas, economia e poder: o estado de Roraima entre 1970 e 20oo. Tese (Doutorado em Desenvolvimento Sustentável do Trópico Úmido). Universidade Federal do Pará, Belém, 2004.

VIEIRA, J. G. Missionários, fazendeiros e índios de Roraima: a disputa pela terra, 1777-1980. Boa Vista: EDUFRR, 2007.

Recebido em 20 de fevereiro de 2017. Aprovado em 12 de março de 2017. 